\title{
A new damage model for composite laminates
}

\author{
Marcelo Leite Ribeiro ${ }^{a}$, Volnei Tita ${ }^{\mathrm{a}, *}$, Dirk Vandepitte ${ }^{\mathrm{b}}$ \\ ${ }^{a}$ Department of Aeronautical Engineering, Engineering School of São Carlos, University of São Paulo, Av. Trabalhador São-Carlense 400, São Carlos, SP, Brazil \\ ${ }^{\mathrm{b}}$ Production Engineering, Machine Design and Automation (PMA) Section, Katholieke Universiteit Leuven, Leuven, Belgium
}

\section{A R T I C L E I N F O}

Article history:

Available online $\mathrm{xxxx}$

\section{Keywords:}

Composite materials

Progressive damage analysis

Material models

Finite element analysis

\begin{abstract}
A B S T R A C T
Aircraft composite structures must have high stiffness and strength with low weight, which can guarantee the increase of the pay-load for airplanes without losing airworthiness. However, the mechanical behavior of composite laminates is very complex due the inherent anisotropy and heterogeneity. Many researchers have developed different failure progressive analyses and damage models in order to predict the complex failure mechanisms. This work presents a damage model and progressive failure analysis that requires simple experimental tests and that achieves good accuracy. Firstly, the paper explains damage initiation and propagation criteria and a procedure to identify the material parameters. In the second stage, the model was implemented as a UMAT (User Material Subroutine), which is linked to finite element software, ABAQUS ${ }^{\mathrm{TM}}$, in order to predict the composite structures behavior. Afterwards, some case studies, mainly off-axis coupons under tensile or compression loads, with different types of stacking sequence were analyzed using the proposed material model. Finally, the computational results were compared to the experimental results, verifying the capability of the damage model in order to predict the composite structure behavior.
\end{abstract}

(c) 2011 Elsevier Ltd. All rights reserved.

\section{Introduction}

In the last years, the use of composite materials as a primary structural element has increased. Some new aircraft designs, such as Airbus A380 and Boeing 787 use composite materials even for primary structural elements (e.g. wing spars and fuselage skins), achieving lighter structures without loss of airworthiness. However, the application of composites in structures is still limited by the difficulty in predicting their service life [1].

Although the increasing number of failure criteria and progressive failure models as proposed by Puck and Schürmann [2], Travessa [1], and others [3], the failure process and subsequent damage evolution is still a challenge to be overcome, mainly for large and complex aeronautical structures. Also, the difficulty in predicting the structural failure modes requires a better planned test program [3]. Another concern is about composite materials properties. Tensile strength and inter-laminar fracture toughness were improved [4]. However, compression failure is still a design limiting factor for aligned continuous long fibers composites, in which the compressive strength is often lower than $60 \%$ of tensile strength [5]. The compression behavior of composite laminates is very complex, due to many concurrent phenomena. Fiber micro-buckling, splitting and shear band [6] are some effects, which should be considered, as well as matrix damage and deformation. The matrix phase

\footnotetext{
* Corresponding author. Tel.: +55 163373 8612; fax: +55 1633739590.

E-mail address: voltita@sc.usp.br (V. Tita).
}

has an essential role in composites for transmitting the stresses to fibers, protecting the fibers and providing an alternative path to the load when a fiber breakage [7]. Thus, classical damage mechanics is being used by several authors to model the failure behavior of composite materials, mainly the polymer matrix phase. Pavan et al. [8], using damage mechanics approach, formulate a model accounting for the visco-elastic effects in the damage failure of composite. Flatscher and Pettermann [9] performs an analysis of an open hole specimen subjected to uniaxial tensile effort combining damage and plasticity.

Therefore, it is possible to observe many contributions at literature for predicting the mechanical behavior of composite structures [1-3,8-17], but, normally, there are many difficulties to overcome due to the complex response of composite materials. These difficulties are based onto perform some experimental tests, manufacturing process of tests coupons and/or computational simulations with low cost. Thus, a new material model, combining different theoretical models with new considerations, is developed to predict the failure of composite structures. Also, this material model has to perform the progressive damage analysis of the composite structures until their complete collapse under any load condition, using conventional experimental tests in simple tests coupons and simulations with low computational costs, while still maintaining good accuracy. In order to verify if these requirements are reached, the new material model is implemented as a UMAT (User Material Subroutine), which is linked to finite element software, ABAQUS ${ }^{\mathrm{TM}}$. Afterwards, some case studies, mainly 
off-axis coupons under tensile or compression loads with different types of stacking sequence are analyzed, using the proposed material model. Finally, the computational results are compared to the experimental results, verifying the capability of the damage model to predict the composite structure behavior.

\section{Failure mechanisms and theoretical models}

Due to composite materials heterogeneity, composite structures exhibit multiple types of damage before total laminate rupture. Thus, failure of composite materials and structures is very complex and not well defined. The failure process involves a different number of failure mechanisms, such as fiber fracture, fiber pull out, matrix cracking, fiber debonding, fiber kinking, interface cracks and fiber splitting. When the fibers are the primary load carrying component, the most critical failure mechanism is the transverse fiber fracture, which leads to a rupture of a continuous fiber into two or more distinct segments [10]. Summarizing, composite laminates made from the stacking of unidirectional plies, with a polymer matrix reinforced by fibers, show two types of failure modes:

1. Intra-ply failure modes: damage at fibers, polymer matrix and/or interface between fibers and matrix (Fig. 1a).

2. Inter-ply failure modes: delaminations between plies (Fig. 1b).

Considering intra-ply failure, mechanism 4 in Fig. 1a is known as fiber rupture [27]. However, the fiber failure mode depends on the type of loading, for example, compression loads can induce micro-buckling, but tensile loads can induce rupture of fibers. The intra-ply damage at the matrix depends on the ductility of the polymer, as well as the in-service temperature. Thus, the polymeric matrix can present a brittle or an inelastic behavior

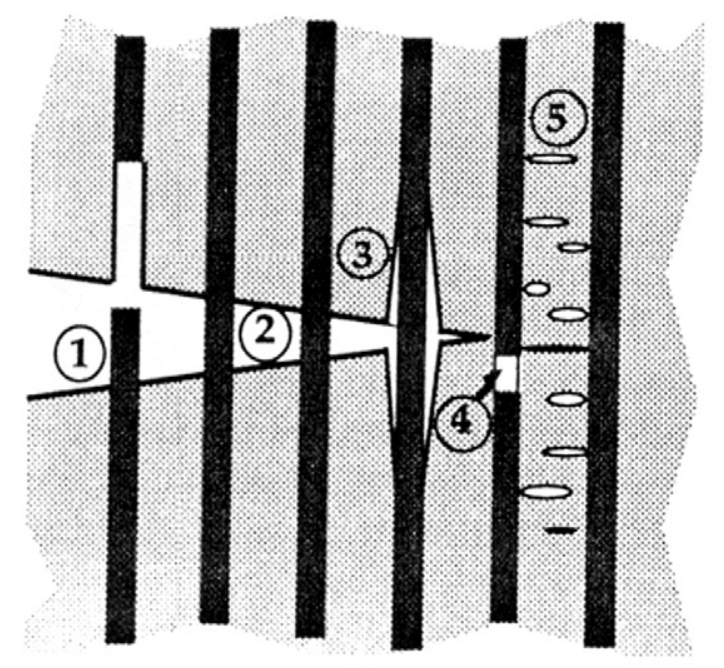

(a)

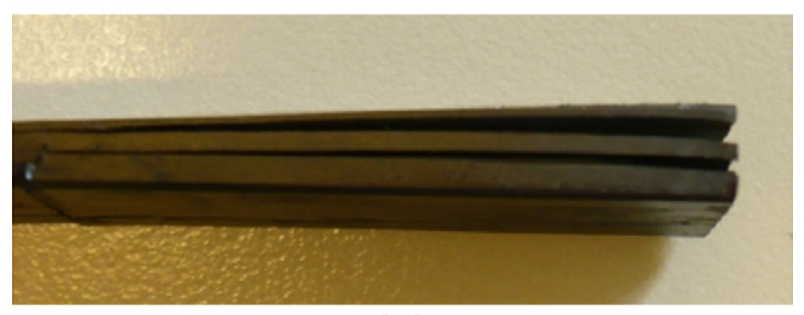

(b)

Fig. 1. (a) Intra-ply failure of composite [27]; (b) inter-ply failure of composite (delamination). (mechanism 5). Mechanism 1, called "Pull-Out", occurs when the interface between fiber and matrix is weak. The fiber is pulled out of the matrix after the debonding mechanism (mechanism 3) occurred. If the interface between fiber and matrix is strong, the fiber is not pulled out of the matrix, and the mechanism 2 called "Fiber Bridging" is activated. The inter-ply failure, called delamination (Fig. 1b), occurs after intra-ply damage, i.e., the evolution of intra-ply damage leads to the delaminations, because the damaged regions propagate when the load increases. Also the cracks at two adjacent plies (with different orientation angle) join for creating a discrete failure between these layers. At that moment, the interlaminar shear increases strongly and the delamination process initiates. This failure mechanism is very common to occur under flexural and transverse shear stresses due to quasi-static or dynamic loading. Theoretical models for intra-ply damage have been improved and other mathematical models for delamination have been developed [11].

Under compression loads, laminate failure mostly occurs due to elastic instability of the fibers [2]. However, the compression failure mechanism is more complex and depending of the material properties. Also, different compressive failure modes are possible e.g. micro-buckling, kinking and fiber failure [12].

The most popular numerical technique used for structural analysis is the Finite Element Method, which allows modeling complex structures providing displacements, strains and stresses components. Based on the stress components, it is possible to carry out the progressive failure analysis using a theoretical model and strength values. However, it may not be a simple task, mostly when a progressive failure analysis is performed. Some models demand a high computational effort and the analysis time may be considerable. Also, material with softening behavior and stiffness degradation normally presents severe numerical convergence problems, mostly when using implicit finite element programs [13]. However computational simulations can reduce the characterization costs of composite materials and support the optimization of these materials [14]. Xiao [15] showed that some damage parameters model can be estimated by correlations between computational simulations with standard material test results.

Therefore, some effects of damage due to creation of free surfaces and discontinuity can be detected by the reduction of stiffness, yield stress, hardness, ultrasonic wave velocity, density, etc. [16]. Some of these physical effects allow measuring the damage in an inverse way. The damage mechanics approach has been used by several authors to simulate the damage process (initiation and propagation), as well as the progressive failure analysis, which requires the identification of the first ply failure. For this task, there are many types of failure theories available in the current literature. Due to simplicity of use, the early theories, for example, Tsai-Wu, maximum stress, maximum strain and Hashin are still applied in analysis of laminate [17] in order to identify the initial failure.

\subsection{Longitudinal failure}

When a unidirectional (UD) composite lamina is loaded in fiber direction (Fig. 2a), the largest portion of the load is transferred by the fibers due to their high stiffness compared to the matrix. Also, the transmission of tensile loads in the fibers is not influenced by the state of damage in the matrix [18]. However, the behavior of unidirectional lamina varies with several factors such as fiber volume fraction, matrix material, fiber material, manufacturing process and compressive or tensile load. After fiber failure, the internal loads are redistributed and it may cause a structural collapse [3]. In UD composites, intralaminar failure mechanisms trigger structural collapse almost immediately, but multidirectional composites can support an increase of intralaminar failure before collapse [3]. 


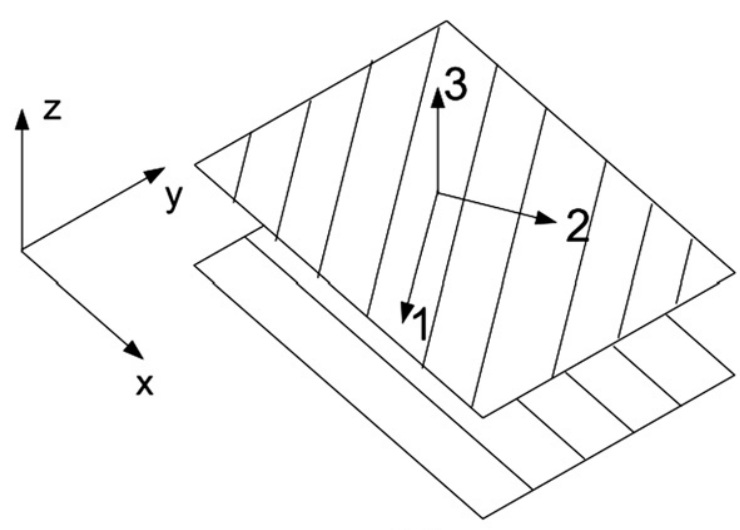

(a)

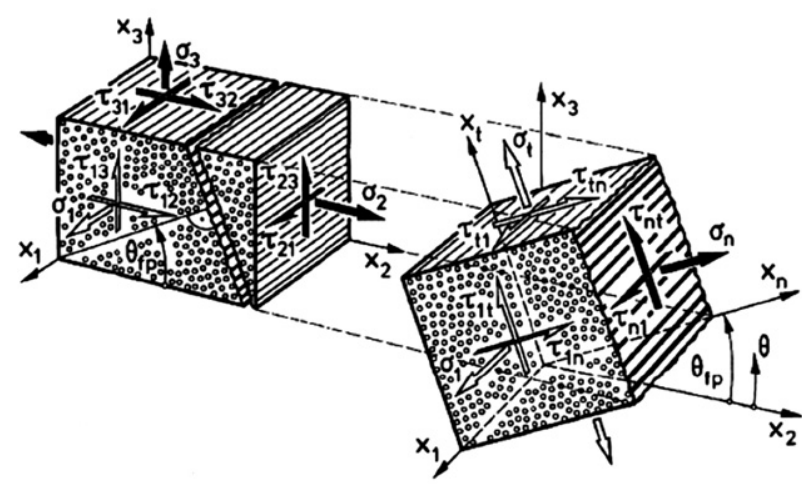

(b)

Fig. 2. (a) Lamina coordinate system; (b) failure plane orientation [22].

Assuming that the fiber limit strain value $\varepsilon_{f}^{*}$ is lower than the matrix limit strain value $\varepsilon_{m}^{*}$, which is plausible for most composites, when this unidirectional composite lamina is loaded in fiber direction, fibers will fail before the matrix. The majority of load supported by the fibers will be transferred to the matrix. However, under tensile loads, the fibers tend to straighten, which may contribute to matrix damage [10].

Under compressive load in fiber direction, the composite failure is considered to be a micro-buckling problem. This phenomenon is influenced by several factors such as fiber size and shape, fiber waviness, fiber-matrix bonding, fiber and matrix stiffness and strength [10]. The compressive load carrying capacity is severely affected by the effective stiffness and strength of matrix. The matrix works as an elastic base for the fibers under compression [18].

Whereas fiber tensile strength $X_{T}$ can be regarded as the true fiber tensile strength, fiber compressive strength $X_{C}$ is usually not the true fiber compressive strength, because compressive failure mostly occurs through elastic instability [2]. Also, compressive strength of composite materials is highly dependent on the fiber alignment, which low values of misalignment can lead to a drastic reduction on the compression stiffness and strength $[4,19]$.

\subsection{Transverse failure}

The transverse behavior of unidirectional composite materials is highly anisotropic with low strength in the direction 2 (Fig. 2a). Even when loaded in fiber direction, the composite could fail in transverse direction with several factors, showing a significant influence on the strength [20]. In the transverse direction, the normal and shear stresses are transmitted by both matrix and fibers. However, the damage occurs in the matrix and in the fiber-matrix interface. Usually, the bond strength between fiber and matrix is lower than the strength of each single constituent [18].

The failure in the transverse direction encompasses both matrix cracking and fiber-matrix debonding [3]. Puck and Schürmann [2] assumed that UD carbon fiber-epoxy and glass fiber-epoxy composites behave in a very brittle way at failure, without previous apparent inelastic deformation. This brittle behavior can be better modeled using Mohr failure criteria [21]. The failure criterion proposed by Puck and Schürmann [2] is based on physical considerations, containing information about fracture angle. Beside, low computational capacity is required, when limited to a plane stress state.

Under transverse tensile loading, $\sigma_{22}>0$ and in-plane shear stress $\tau_{12}$, the existing defects that are presented in a ply (small debonds, voids, resin rich regions) trigger a transverse crack, which extends through the ply thickness [3]. These defects produce a non-linear behavior. Thus, the relation between shear stress $\tau_{12}$ and shear strain $\varepsilon_{12}$ is non-linear before the failure. This behavior is also due to visco-plasticity of the matrix [22]. These transverse cracks do not produce any effect in the fibers.

Under transverse compressive load, $\sigma_{22}<0$, matrix cracks crush in the sense of "fragmentation" of brittle matrix materials [18]. If the normal stress acting in the failure plane is compressive, $\sigma_{n}<0$, the failure is due to plane shear stresses, $\tau_{n l}$ and $\tau_{n t}$. For this case, $\sigma_{n}$ prevents the shear fracture [22]. Fig. $2 \mathrm{~b}$ shows the notations and coordinate system for unidirectional composite and the plane of fracture. Also, in the presence of transverse compressive stress, $\sigma_{22}<0$, crack closure allows that forces to be transmitted through the cracks. Schuecker and Pettermann [23] regard this effect as stiffness recovery for shear modulus.

Another important feature of composite failure in transverse direction is how the shear stress affects the failure plane angle. Under a high value of in-plane shear stress, when compared with transverse stress $\left(\tau_{12}>\sigma_{22}\right)$, the fracture plane is perpendicular to the mid-plane. Increasing $\sigma_{22}$, the fracture plane angle changes [3].

\section{Material model}

Some of the literature models require complex experimental test devices, procedures or coupons, which despite the model accuracy. This imposes additional difficulties in failure analysis due to the identification process of model parameters. Also, sometimes high computational resources are required. In order to overcome those difficulties, the proposed material model should meet the following objectives:

- Be simple to be implemented.

- Possess low computational cost.

- Require only simple tests for model parameter identification.

- Require only simple test coupons to be manufactured.

- Good accuracy.

The present work regards the composite lamina under plane stress state and the damage is regarded to be uniform across the layer thickness [10]. Table 1 shows the symbols used in this work.

\subsection{Fiber behavior model}

Under tensile load in fiber direction, the unidirectional composite lamina behavior is linear elastic with brittle fracture [24,25]. The model assumes that the fiber behavior is not influenced by the damage state in the matrix. Thus, for tensile load in fiber direction, the maximum stress criterion is used to identify the fiber failure as follows: 
Table 1

List of symbols.

\begin{tabular}{|c|c|}
\hline$\sigma_{11}, \sigma_{22}, \tau_{12}$ & $\begin{array}{l}\text { Stress in fiber direction, stress in transverse direction and } \\
\text { shear stress }\end{array}$ \\
\hline$\sigma_{22_{0}}$ & Linear to non-linear limit value in $\sigma_{22} v s . \varepsilon_{22}$ curve \\
\hline$\sigma_{22 y}$ & $\begin{array}{l}\text { Linear to non-linear limit value in } \sigma_{22} v s . \varepsilon_{22} \text { curve for off-axis } \\
\text { lamina }\end{array}$ \\
\hline$\hat{\sigma}_{11}$ & Effective stress in fiber direction \\
\hline$\hat{\sigma}_{22}$ & Effective stress in transverse direction \\
\hline$\hat{\sigma}_{12}$ & Effective shear stress \\
\hline$\theta$ & Ply orientation angle \\
\hline$S_{12 y}$ & Linear to non-linear limit value in $\tau_{12} v s . \gamma_{12}$ curve \\
\hline$\varepsilon_{11}, \varepsilon_{22}, \gamma_{12}$ & Strain in fiber direction, transverse direction and shear strain \\
\hline$X_{T}$ & Fiber strength value under tensile \\
\hline$X_{C_{0}}$ & Fiber linear behavior limit value under compression \\
\hline$f\left(\varepsilon_{11}\right)$ & $\begin{array}{l}\text { Strain dependence function under compression in fiber } \\
\text { direction for secant modulus }\end{array}$ \\
\hline$f\left(\varepsilon_{22}\right)$ & $\begin{array}{l}\text { Strain dependence function under compression in transverse } \\
\text { direction for secant modulus }\end{array}$ \\
\hline$f$ & Elastic domain function \\
\hline$E_{11_{0}}, E_{22_{0}}, G_{12_{0}}$ & $\begin{array}{l}\text { Initial value of elastic modulus in fiber direction, transverse } \\
\text { direction and shear modulus }\end{array}$ \\
\hline$d_{1}$ & Damage variable related with $\sigma_{11}$ \\
\hline$d_{2}$ & Damage variable related with $\sigma_{22}$ \\
\hline$d_{6}$ & Damage variable related with $\tau_{12}$ \\
\hline$E_{D}$ & Strain energy density \\
\hline$E_{D_{c}}$ & Strain energy density limit \\
\hline
\end{tabular}

$\frac{\sigma_{11}}{X_{T}} \leqslant 1$

After failure under tensile loads, the Young's modulus in fiber direction $E_{11}$ is degraded to zero. To account this effect in the compliance matrix (see Eq. (9)), the damage variable $d_{1}$ is equal to " 1 ".

Regarding the behavior under compression loads in fiber direction, a unidirectional composite can be assumed to possess a linear elastic behavior until a specified value, after that, a non-linear elastic behavior should be adopted. Thus, the linear elastic to non-linear elastic limit, $X_{C_{0}}$, is identified similarly to tensile failure as shown in Eq. (2):

$\frac{\left|\sigma_{11}\right|}{X_{C_{0}}} \leqslant 1$

After $\left|\sigma_{11}\right| \geqslant X_{C_{0}}$, any increase in the compression loads in fiber direction results in a non-linear elastic stress-strain behavior. This non-linear elastic behavior is simulated using a secant modulus as shown by the following equation:

$E_{11}=\frac{X_{C_{0}}}{\left|\varepsilon_{11}\right|}\left(1-f\left(\varepsilon_{11}\right)\right)+f\left(\varepsilon_{11}\right) E_{11_{0}}$

In Eq. (3), the $E_{11}$ is function of $\varepsilon_{11}$. As adopted for tension, the damage state in the matrix is not affected by the compression behavior of the fibers.

\subsection{Matrix behavior model}

The damage process in the matrix is mainly caused by $\sigma_{22}$ and $\tau_{12}$. The model assumes that stress in fiber direction does not affect the damage state in the matrix.

A non-linear behavior could be observed in some experimental tests in composite materials, mostly when the fibers and load are not aligned. This non-linear behavior is due to inelastic deformations and damage in matrix [2]. In order to model the damage process in the matrix, the damage parameters $d_{2}$ related to $\sigma_{22}$ and $d_{6}$ related to $\tau_{12}$ are considered, which range from " 0 ", for undamaged material, to "1", for complete damaged material. These damage variables are related to the stress, using the hypothesis of effective stress, which is applied on the damaged area [10]. The effective stresses are given by the following equation:

$$
\left\{\begin{array}{l}
\hat{\sigma}_{11} \\
\hat{\sigma}_{22} \\
\hat{\sigma}_{12}
\end{array}\right\}=\left[\begin{array}{ccc}
\frac{1}{1-d_{1}} & 0 & 0 \\
0 & \frac{1}{1-d_{2}} & 0 \\
0 & 0 & \frac{1}{1-d_{6}}
\end{array}\right]\left\{\begin{array}{l}
\sigma_{11} \\
\sigma_{22} \\
\tau_{12}
\end{array}\right\}
$$

Another important concept is adopted; the thermodynamic forces that relate the damage variables with strain energy density $E_{D}$ (Eq. (5)) for the polymeric matrix [24]. Eq. (5) shows only the thermodynamic forces applied on the matrix.

$Y_{2}=\frac{\partial E_{D}}{\partial d_{2}}, \quad Y_{6}=\frac{\partial E_{D}}{\partial d_{6}}$

The damaged strain energy density for the matrix is written in terms of effective stresses is shown by Eq. (6) [10].

$E_{D}=\frac{1}{2}\left[\frac{\left\langle\sigma_{22}^{2}\right\rangle_{+}}{E_{22_{0}}\left(1-d_{2}\right)}+\frac{\left\langle\sigma_{22}^{2}\right\rangle_{-}}{E_{22_{0}}}+\frac{\left\langle\tau_{12}^{2}\right\rangle_{+}}{G_{12_{0}}\left(1-d_{6}\right)}\right]$

Under tensile stress in the matrix, the micro-cracks and microvoids open. When the load increases, the stress state can accelerate the propagation of the micro-cracks and micro-voids. This propagation is accounted by the damage variables $d_{2}$ and $d_{6}$ evolution. Under compression, the micro-cracks and micro-voids tend to close [10], thus the damage parameter $d_{2}$ is regarded not to change. However, the damage parameter $d_{6}$ can change. The shear stress damage parameter does not depend on the sign of the shear stress.

The initiation of damage in composite structures can be identified by stiffness reduction. This behavior can be evaluated by performing a cyclic tensile or compression test. During loadunload-load cycle, it is possible to observe this stiffness reduction compared to the initial stiffness (Fig. 3). The present model assumes that the damage process, as well as the non-linear behavior initiates, when the stress-strain curve is no longer linear.

The off-axis coupon damage measurement shows that the intensity of $d_{2}$ is different compared to $d_{2}$ that is obtained by $[90]_{n}$. Also, for each off-axis orientation, the damage state depends on $\sigma_{22}$ and $\tau_{12}$. It is possible to find at literature, a procedure to calculate the coupling parameter [24,25]. This model assumes that $d_{2}$ and $d_{6}$ are function of the orientation angle and thermodynamic forces $Y_{2}$ and $Y_{6}$ respectively, which indirectly accounts for $\sigma_{22}$ and $\tau_{12}$ coupling. Besides, the damage measurements show that the damage evolution for $d_{2}$ and $d_{6}$ can be regarded as linear. Thus $d_{2}$ is equal to $A(\theta) Y_{2}+B(\theta)$ and $d_{6}$ is equal to $C(\theta) Y_{6}+D(\theta)$. The functions $A(\theta)$ and $C(\theta)$ are linear functions, $B(\theta)$ and $D(\theta)$ are the threshold values when $f \geqslant 0$ (see Eq. (7)).

Despite of the fact that $\tau_{12}$ does not affect the damage state evolution, a compressive value of $\sigma_{22}$ affects the evolution of $d_{2}$. Under

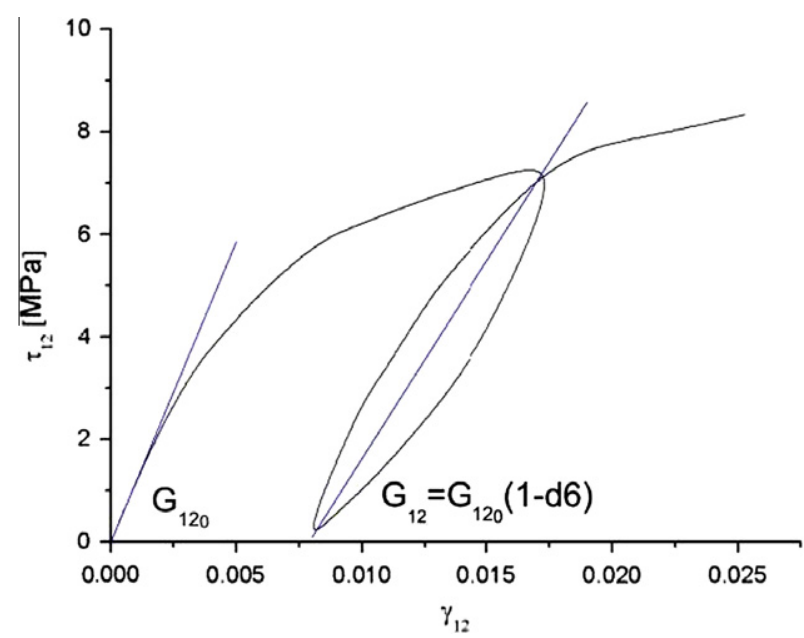

Fig. 3. Typical damage behavior of shear modulus and damage measurement. 
compressive $\sigma_{22}$, the cracks and voids tend to close; so $d_{2}$ does not change. As observed by experimental tests, coupons $[90]_{n}$ under compression behave almost like composite in fiber direction compression (with non-linear elastic response). To model the transverse direction under compression, the secant modulus is used again.

Accounting for some experimental tests results of $90^{\circ}$ and offaxis coupons, the linear elastic limit for $\tau_{12}$ and $\sigma_{22}$ is taken and plotted in $\sigma_{22}$ vs. $\tau_{12}$ plane for each coupon. Based on the interpolation of experimental data, a failure surface can be obtained as described by Eq. (7). It is important to verify that the proposed surface only depends on parameters that are obtained by shear $\left(S_{12 y}\right)$ and compression or tensile $\left(\sigma_{22_{0}}\right)$ standard test.

$f=\sqrt{\sigma_{22}^{2}+\tau_{12}^{2}}-\left(-S_{12_{y}}+\frac{2 S_{12_{y}}}{1+\left(\left|\sigma_{22}\right| / \sigma_{22_{0}}\right)^{3}}\right)$

Fig. 4 shows the linear elastic limit surface and the average values of $\sigma_{22}$ and $\tau_{12}$ for each orientation. The onset of non-linear behavior occurs, when the state of stress leads to $f \geqslant 0$. Under compressive stress $\sigma_{22}$, as mentioned before, a secant modulus is used to model the non-linear behavior in transverse direction as shown by the following equation:

$E_{22}=\frac{\sigma_{22 y}}{\left|\varepsilon_{22}\right|}\left(1-f\left(\varepsilon_{22}\right)\right)+f\left(\varepsilon_{22}\right) E_{22_{0}}$

where the factor $\sigma_{22 y}$ is assumed the value of $\sigma_{22}$ when $f \geqslant 0$, because, for this model, the non-linear behavior can initiate with different values of $\sigma_{22}$ than obtained by compression tests on $90^{\circ}$ coupons (see Fig. 4).

Also, the brittle fracture for matrix is regarded to happen when $E_{D}$ reaches the limit value $\left(E_{D_{C}}\right)$ obtained by experimental tests. Thus, when $\mathrm{E}_{\mathrm{D}}>\mathrm{E}_{\mathrm{D}_{\mathrm{C}}}$, then $d_{2}$ is equal to "1" and $d_{6}$ is equal to "1". Finally, the new material model is summarized in Table 2.

Using classical damage mechanics and proposing some adjustments for the Poisson's ratios in order to take account the damage effect, compliance tensor is given by [18]:

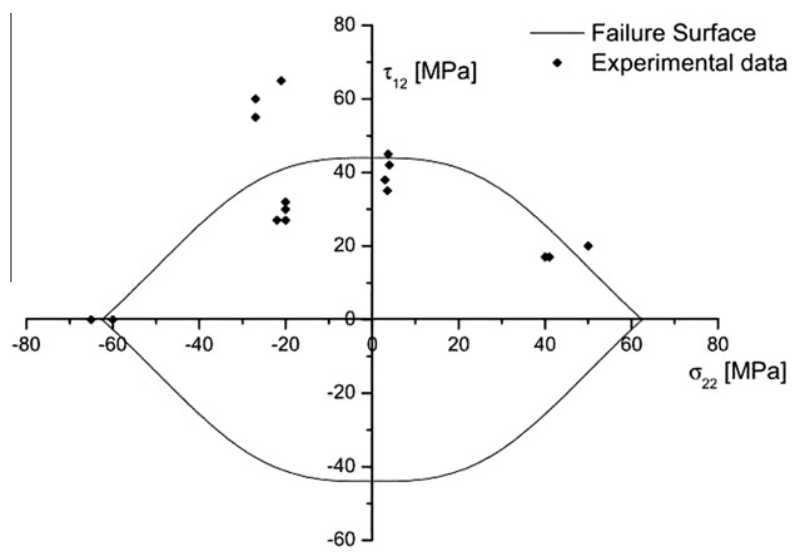

Fig. 4. Linear elastic domain $f$ and experimental points.

Table 2

Material model summary.

\begin{tabular}{lll}
\hline Failure criteria & Mode of failure & Degradation law \\
\hline$\frac{\sigma_{11}}{X_{T}} \leqslant 1$ & Fiber tensile & $E_{11}=0$ \\
$\frac{\left|\sigma_{11}\right|}{X_{c_{0}}} \leqslant 1$ & Fiber compression & $E_{11}=\frac{X_{C_{0}}}{\left|\varepsilon_{11}\right|}\left(1-f\left(\varepsilon_{11}\right)\right)+f\left(\varepsilon_{11}\right) E_{11_{0}}$ \\
$f \geqslant 0$ & Matrix tensile & $d_{2}=A(\theta) Y_{2}+B(\theta)$ \\
$f \geqslant 0$ & Matrix compression & $E_{22}=\frac{\sigma_{22 y}}{\left|\varepsilon_{22}\right|}\left(1-f\left(\varepsilon_{22}\right)\right)+f\left(\varepsilon_{22}\right) E_{22_{0}}$ \\
$f \geqslant 0$ & Shear & $d_{6}=C(\theta) Y_{6}+D(\theta)$ \\
\hline
\end{tabular}

$$
D=\frac{1}{K}\left[\begin{array}{ccc}
\left(1-d_{1}\right) E_{11} & \left(1-d_{1}\right)\left(1-d_{2}\right) v_{21} E_{22} & 0 \\
\left(1-d_{1}\right)\left(1-d_{2}\right) v_{12} E_{11} & \left(1-d_{2}\right) E_{22} & 0 \\
0 & 0 & K\left(1-d_{6}\right) G_{12}
\end{array}\right]
$$

where $K=\left(1-\left(1-d_{1}\right)\left(1-d_{2}\right) v_{12} v_{21}\right)$. In order to avoid the material self-healing, the damage parameters $d_{1}, d_{2}$ and $d_{6}$ are the maximum calculated value along the load history analyses.

\section{Experimental tests}

In order to identify the material model parameters, the standard tests for tensile, shear and compression, and some additional off-axis and angle-ply experimental tests are required (Table 3).

Some special considerations must be taken in performing offaxis tests, for example, it is very difficult to apply only a uniaxial stress state in an off-axis test coupon due to test machine clamps. Due to this effect, the stress component $\tau_{x y}$ is also present. A detailed discussion about off-axis experimental tests is presented by literatures [10,26]. Herakovich [10] shows that the test coupon aspect ratio and lamina orientation have a significant influence for obtaining $\tau_{x y}$. Also, Pierron and Vautrin [26] show the effects caused by the end tabs, when off-axis coupons are tested.

After material characterization and model parameters identification, other tests were performed to evaluate the advantages and limitations of the proposed material model. These tests consist of off-axis $[15]_{10}$ and $[30]_{10}$ under compression loads. It is important to mention that those coupons were not used for material characterization under compression, because the coupon aspect ratios are too low. Despite that, these are good test coupons to verify the model, once these lead to a complex load case.

It is important to mention that the coupons had resin epoxy as matrix and carbon fiber as reinforcement, manufactured on a filament winding machine. The dimensions of the coupons follow the ASTM standards for each test performed even for off-axis coupons $[15]_{10}$ and $[30]_{10}$ as well as for angle-ply $\left[ \pm 67.5^{\circ}\right]$ coupons (Table 3).

Fig. 5a shows the device for the compression test and the image correlation system. Fig. $5 b$ shows the $[0]_{10}$ coupon for compression test. The experimental tests were performed using strain gages and image correlation system. The experimental tests were performed at USP (University of São Paulo - Brazil) and KU Leuven (Katholieke Universiteit Leuven - Belgium).

At USP, an Emic test machine, strain gages and image correlation system were used. At KU Leuven, an Instron universal test machine was used for compression tests. Strain-gages were used in one test coupon face and digital image correlation in another face. A LIMESS system with VIC2D software was used for the digital image correlation analysis. On the other hand, at USP, the image correlation equipment consists on a Canon camera and

Table 3

Experimental tests.

\begin{tabular}{llll}
\hline Test & Standard & $\begin{array}{l}\text { Specimen } \\
\text { dimensions }(\mathrm{mm})\end{array}$ & $\begin{array}{l}\text { Properties and } \\
\text { model parameters }\end{array}$ \\
\hline Tensile $0^{\circ}$ & ASTM D3039 & $250 \times 15 \times 1$ & $E_{11}, v_{12}, X_{T}$ \\
Tensile $90^{\circ}$ & ASTM D3039 & $175 \times 25 \times 2$ & $E_{22}, d_{2}, Y_{T}$ \\
Tensile $\pm 67.5^{\circ}$ & ASTM D3039 & $175 \times 25 \times 2$ & $d_{2}$ and $d_{6}$ \\
Tensile $5^{\circ}$ & ASTM D3039 & $175 \times 25 \times 2$ & $d_{2}$ and $d_{6}$ \\
In-plane shear $\pm 45^{\circ}$ & ASTM D3518 & $250 \times 25 \times 2.7$ & $G_{12}, S_{12}, d_{6}, S_{12_{y}}$ \\
Compression $0^{\circ}$ & ASTM D3410 & $150 \times 10 \times 2$ & $X_{C_{0}}, X_{C}, \sigma_{11_{0}}$ \\
Compression $90^{\circ}$ & ASTM D3410 & $150 \times 10 \times 2$ & $Y_{C}, \sigma_{22_{0}}, E_{D_{C}}$ \\
\hline
\end{tabular}




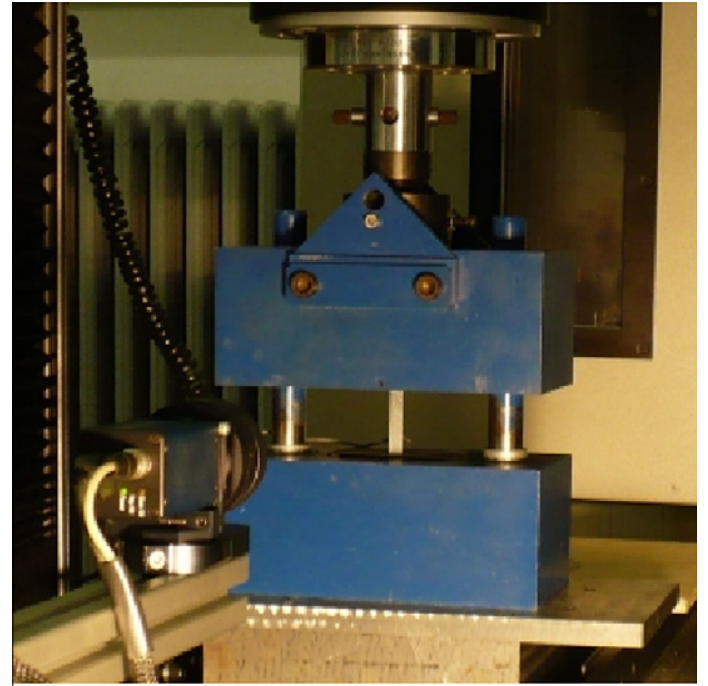

(a)

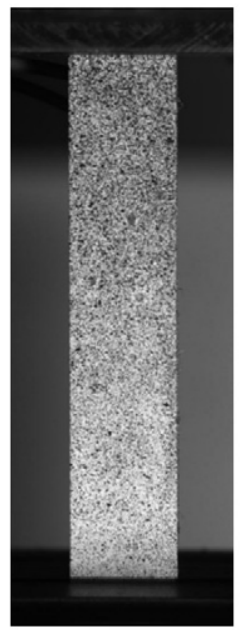

(b)

Fig. 5. (a) Compression test setup and data acquisition system (LUMISS and strain gages); (b) $[0]_{10}$ coupon for compression test.

software programmed in Matlab ${ }^{\mathrm{TM}}$ was used. At both places, the force $v$. displacement data were provided by the test machines. A test speed of $0.5 \mathrm{~mm} / \mathrm{min}$ was applied for all experimental tests, both for loading and unloading cycles. In order to avoid low cycle fatigue, the number of cycles is limited to a maximum of five [25].

Performing cyclic experimental tests, the damage variables were measured as shown in Fig. 3. The damage variables $v$ s. thermodynamic force are shown by Fig. 6a, for $d_{2}$ and by Fig. 6b, for $d_{6}$. The damage measurement procedure is the same described at literatures [24,25].

Regarding the evolution of the parameter $d_{2}$ shown by Fig. 6a, it is verified that the ply orientation has an important role in damage evolution. In fact, it is due to an increase in the damage process produced by shear stress. For $d_{6}$, as expected, if the orientation is close to $90^{\circ}$ then the shear damage is lower, but if the ply orientation changes towards $0^{\circ}, d_{6}$ is the principal damage parameter of the polymeric matrix (Fig. $6 a$ and b).

Finally the proposed material model assumes that $d_{2}$ evolves in a linear way. Thus $d_{2}$ evolution equations are fitted as a function of the orientation angle $\theta$. The same procedure is applied for $d_{6}$.

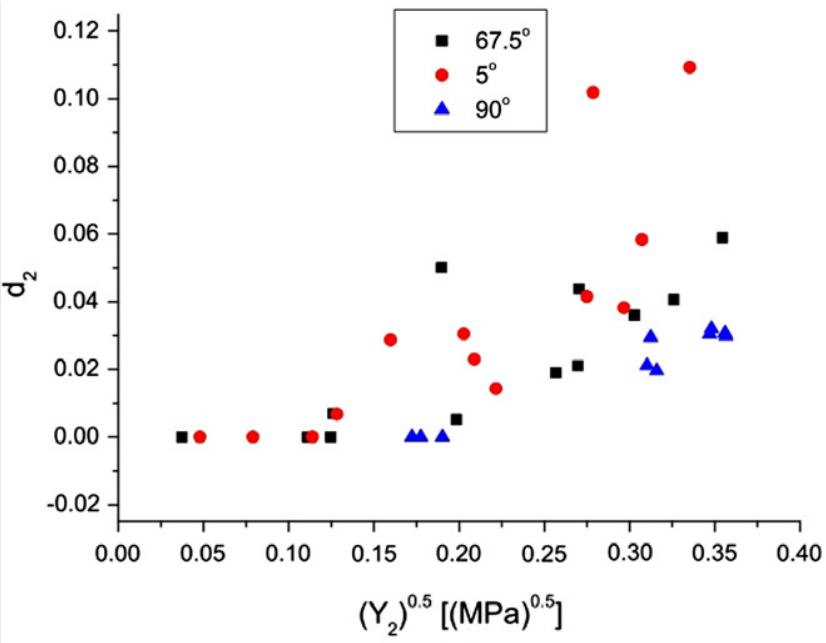

(a)

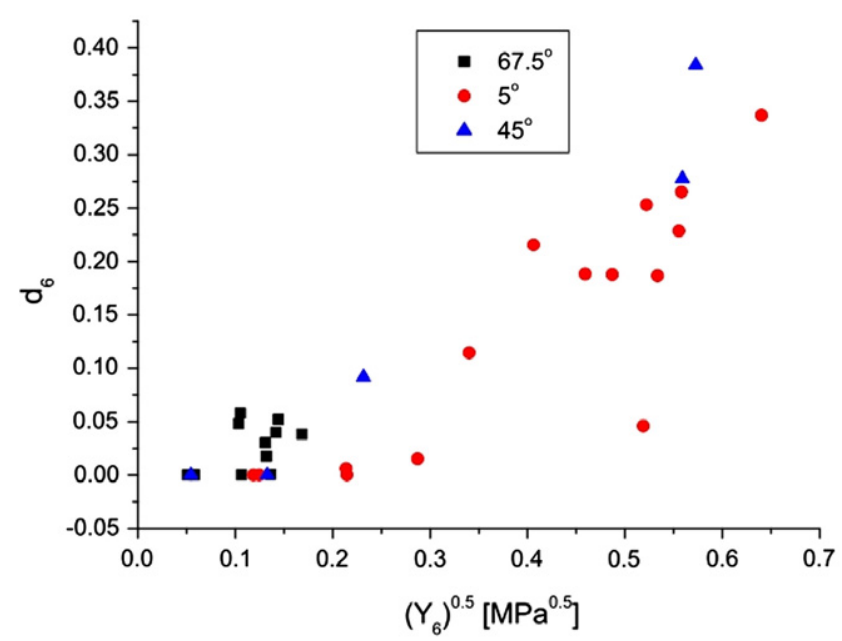

(b)

Fig. 6. (a) $d_{2}$ evolution for some coupons; (b) $d_{6}$ evolution for some coupons.

\section{Results and discussions}

The material model was evaluated using a User Material subroutine (UMAT) programmed in FORTRAN language and the subroutine was linked to ABAQUS ${ }^{\mathrm{TM}}$ finite element program. The finite element model dimensions follow the tensile and compression standards recommendations as used for the experimental test coupons. The computational simulations results were compared to $[15]_{10}$ and $[30]_{10}$ test coupons for compression and to $[5]_{10}$ for tensile.

Considering off-axis [5] $]_{10}$ under tensile load, Fig. 7 shows $\sigma_{x x} v s$. $\varepsilon_{x x}$ for the experimental test and the computational results. The load is supported not only by the fibers but also by the matrix. As the load increases, the ply stresses in local orientation also increase until failure. The failure process in off-axis $[5]_{10}$ is a mixed mode of fiber and matrix failure as shown in Fig. 8. The failure process initiates with some fibers under high stress. Then the fibers break and the load are redistributed to matrix and nearby fibers. Due to high loads supported by fibers, when failure occurs, the matrix is not capable to support the loads and fails in a brittle way $\left(E_{D}>E_{D_{C}}\right)$.

As mentioned before, the compression behavior of composite materials is quite different than for tensile. In order to verify the 


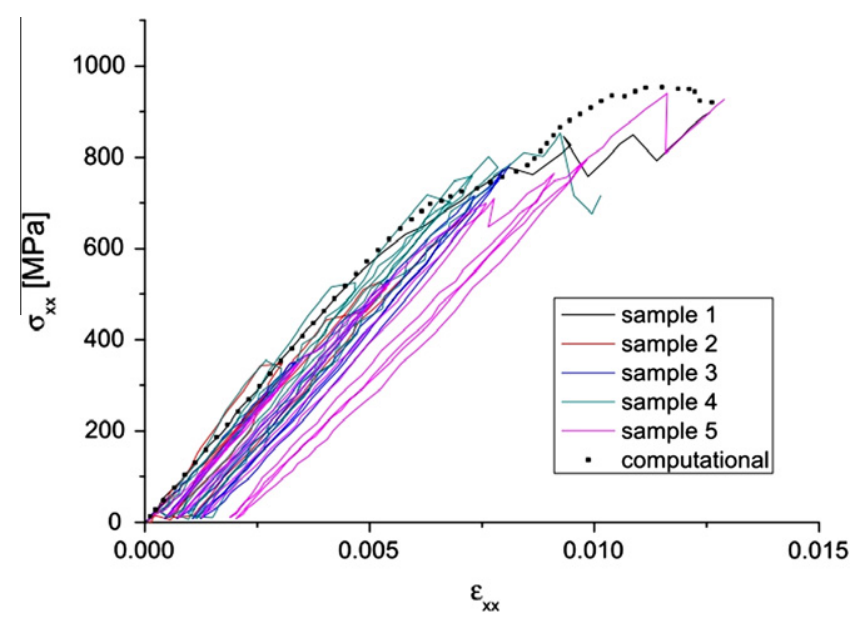

Fig. 7. Tension for off-axis $[5]_{10}$ : experimental tests $v s$. computational results.

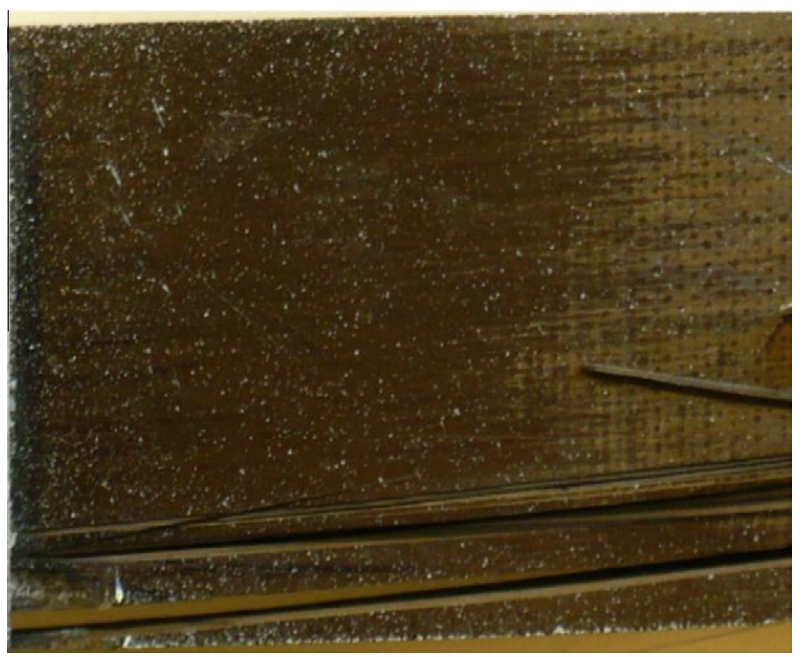

Fig. 8. Failure of off-axis $[5]_{10}$ under tension loads.

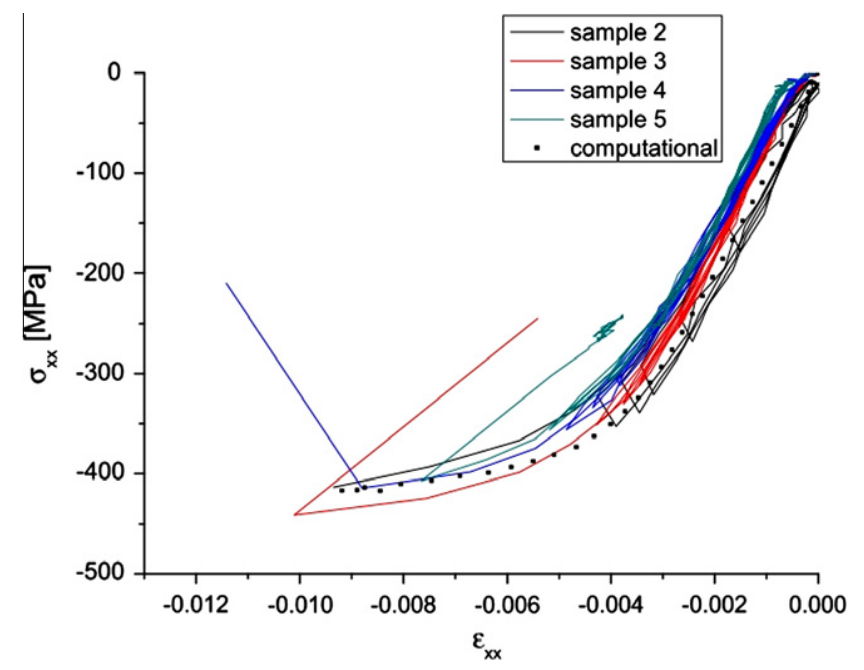

Fig. 9. Compression for off-axis [15 $]_{10}$ : experimental tests $v s$. computational results. advantages and limitations of damage model for predicting the failure under compression loads, numerical results were compared to off-axis $[15]_{10}$ and $[30]_{10}$ compression experimental tests. Also, as mentioned previously, the compression test for off-axis coupons lead to normal stress $\left(\sigma_{x x}\right)$ and shear stress $\left(\tau_{x y}\right)$.

For off-axis [15 $]_{10}$ under compression load, Fig. 9 shows $\sigma_{x x} v s$. $\varepsilon_{x x}$ for the experimental test and the computational results. In this case, similar to tensile for off-axis [5 $]_{10}$, the fibers support most of the load. However, the fiber failure process is more complex than for tensile due to fiber kinking and micro-buckling, which leads to lower failure loads and the failure process is different as shown by Fig. 10 .

The off-axis [30 $]_{10}$ compression results for experimental tests and numerical simulation are shown in Fig. 11. In this case, fibers still support more load than the matrix, but the difference between the load supported by fibers and load supported by matrix is smaller than for the $[5]_{10}$ and $[15]_{10}$. It is very important to comment that the geometry of the coupons also affects the failure process,

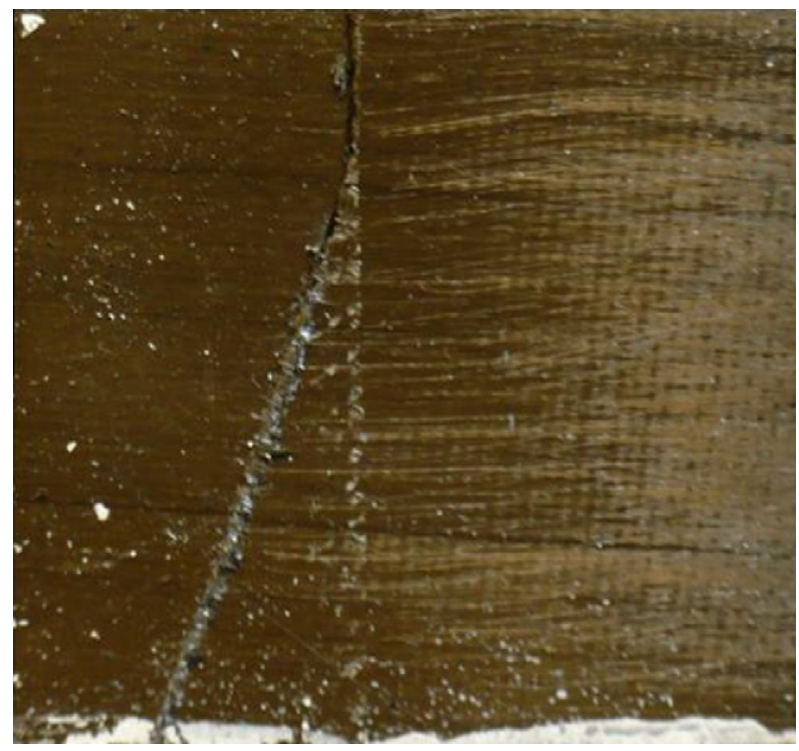

Fig. 10. Failure of off-axis $[15]_{10}$ under compression loads.

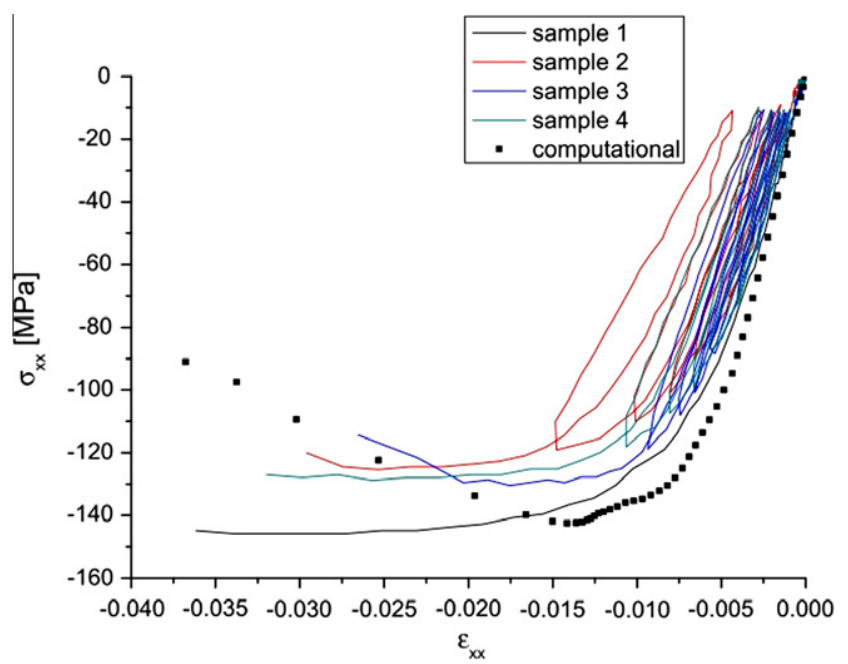

Fig. 11. Compression for off-axis $[30]_{10}$ : experimental tests $v s$. computational results.

\footnotetext{
Please cite this article in press as: Ribeiro ML et al. A new damage model for composite laminates. Compos Struct (2011), doi:10.1016/ j.compstruct.2011.08.031
} 


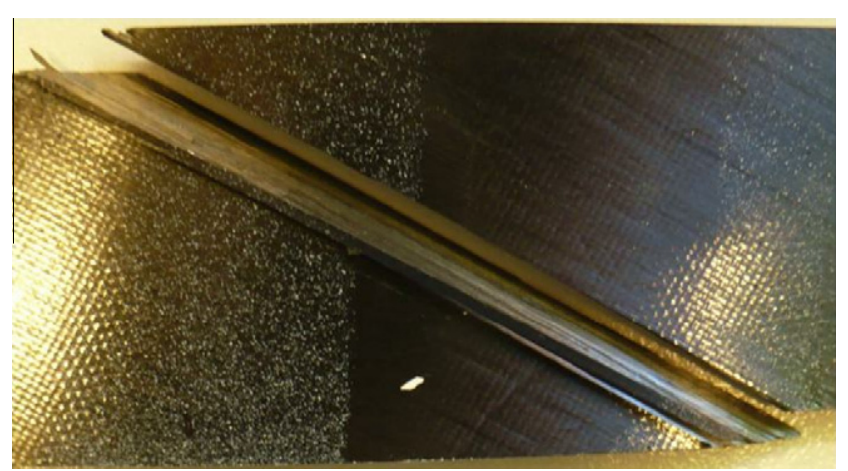

Fig. 12. Failure of off-axis $[30]_{10}$ under compression loads.

in the case for [30 $]_{10}$, there are no fibers crossing all the gage length between the test machine grips. As the polymer matrix load carrying capacity is lower than for fibers, the failure load is lower than for $[15]_{10}$. Thus the coupon failure is governed by the polymeric matrix (Fig. 12).

It is important to mention that the compression test for off-axis $[30]_{10}$ did not fail only due to compressive loads, but buckling was detected for all tested coupons, mostly in the end of the test (for high loads). On the other hand, for off-axis [15 $]_{10}$ coupon, buckling was not detected until close to the failure. Thus, buckling phenomenon can explain the differences observed after failure of $[30]_{10}$ off-axis coupons.

\section{Conclusions}

The new material model can predict the behavior of composite structures for off-axis unidirectional filament wound coupons under tensile or more complex loads cases, e.g. compressive and shear loads.

The simulations were performed with a reasonable computational cost and no convergence problems occur during numerical analyses.

Regarding model parameters, the experimental tests required for identification have a reasonable complexity as the necessary equipment and devices are the same used for usual material characterization as tensile and compression tests. Also, the test coupons are easy to be manufactured and non-conventional geometry or special manufacture processes are not required.

\section{Acknowledgements}

The authors are grateful for the financial support from KU Leuven Arenberg doctoral school, CAPES, São Paulo Research Foundation (FAPESP Process Number: 2009/00544-5), as well as AFOSR and US-Army (Grant Number: FA9550-10-1-0011).

\section{References}

[1] Travessa AT. Simulation of delamination in composites under quasi-static and fatigue loading using cohesive zone models. PhD thesis, Universitat de Girona; 2006.

[2] Puck A, Schürmann H. Failure analysis of FRP laminates by means of physically based phenomenological models. Compos Sci Technol 1998;58(7):1045-67.

[3] Maim P, Camanho P, Mayugo J, Dávila C. A continuum damage model for composite laminates: Part I - Constitutive model. Mech Mater 2007;39(10):897-908.

[4] Yokozeki T, Ogasawara T, Ishikawa T. Nonlinear behavior and compressive strength of unidirectional and multidirectional carbon fiber composite laminates. Compos Part A: Appl Sci Manuf 2006;37(11):2069-79.

[5] Budiansky B, Fleck N. Compressive failure of fibre composites. J Mech Phys Solids 1993;41(1):183-211.

[6] Yokozeki T, Ogasawara T, Ishikawa T. Effects of fiber nonlinear properties on the compressive strength prediction of unidirectional carbon-fiber composites. Compos Sci Technol 2005;65(14):2140-7.

[7] Reid SRZG. Impact behaviour of fibre-reinforced composite materials and structures. Woodhead Publishing Limited; 2000.

[8] Pavan R, Oliveira B, Maghous S, Creus G. A model for anisotropic viscoelastic damage in composites. Compos Struct 2010;92(5):1223-8.

[9] Flatscher T, Pettermann H. A constitutive model for fiber-reinforced polymer plies accounting for plasticity and brittle damage including softening implementation for implicit FEM. Compos Struct 2011;93(9):2241-9.

[10] Herakovich C. Mechanics of fibrous composites. 1st ed.; 1998.

[11] Tita V, Carvalho J, Vandepitte D. Failure analysis of low velocity impact on thin composite laminates: experimental and numerical approaches. Compos Struct 2008;83:413-28.

[12] Pinho ST. Modelling failure of laminated composites using physicallybased failure models. PhD thesis, Imperial College; 2005.

[13] Lapczyk I, Hurtado JA. Progressive damage modeling in fiber-reinforced materials. Compos Part A: Appl Sci Manuf 2007;38(11):2333-41 [CompTest 2006].

[14] Van Der Meer F, Sluys L. Continuum models for the analysis of progressive failure in composite laminates. J Compos Mater 2009;43(20):2131-56.

[15] Xiao X. Evaluation of a composite damage constitutive model for PP composites. Compos Struct 2007;79(2):163-73.

[16] Lemaitre J. A course on damage mechanics; 2005 [ISBN 9773540609804 ].

[17] Tay T, Liu G, Tan SV, Sun CX, Phan D. Progressive failure analysis of composites. J Compos Mater 2008;42:1921-66.

[18] Matzenmiller A, Lubliner J, Taylor RL. A constitutive model for anisotropic damage in fiber-composites. Mech Mater 1995;20(2):125-52.

[19] Wisnom M. The effect of fibre misalignment on the compressive strength of unidirectional carbon fibre/epoxy. Composites 1990;21(5):403-7.

[20] Callister WD. Fundamentals of materials science and engineering. John Wiley \& Sons, Inc.; 2001.

[21] Hashin Z. Failure criteria for unidirectional fiber composites. J Appl Mech 1980;47(2):329-34.

[22] Puck A, Schrümann H. Failure analysis of FRP laminates by means of physically based phenomenological models. Compos Sci Technol 2002;62(1213):1633-62.

[23] Schuecker C, Pettermann H. A continuum damage model for fiber reinforced laminates based on ply failure mechanisms. Compos Struct 2006;76(12):162-73.

[24] Ladeveze P, LeDantec E. Damage modelling of the elementary ply for laminated composites. Compos Sci Technol 1992;43(3):257-67.

[25] Allix O, Ladeveze P, Vittecoq E. Modelling and identification of the mechanical behaviour of composite laminates in compression. Compos Sci Technol 1994;51(1):35-42.

[26] Pierron F, Vautrin A. The 10 off-axis tensile test: a critical approach. Compos Sci Technol 1996;56(4):483-8.

[27] Anderson T. Fracture mechanics - fundamentals and applications. 2nd ed.; 1995. 